MATHEMATICA, 60 (83), $\mathrm{N}^{\circ}$ 2, 2018, pp. 140-148

\title{
NEW RIEMANN-LIOUVILLE FRACTIONAL INTEGRAL RESULTS FOR ACZÉL TYPE INEQUALIES
}

\author{
MOHAMED DOUBBI BOUNOUA, ZOUBIR DAHMANI, and ABDELKADER \\ BENZIDANE
}

\begin{abstract}
In this paper, using the Riemann-Liouville integral operator, we establish several fractional refinements of the Aczél inequality. Some classical results on this famous inequality can be deduced as some special cases of our results.
\end{abstract}

MSC 2010. 26D15, 26A33, 60E15.

Key words. Integral inequality, Aczél inequality, Riemann-Liouville integral.

\section{REFERENCES}

[1] J. Aczél, Some general methods in the theory of functional equations in one variable. New applications of functional equations (in Russian), Uspekhi Mat. Nauk, 11 (1956), 3-68.

[2] S. Belarbi and Z. Dahmani, On some new fractional integral inequalities, J. Inequal. Pure Appl. Math., 10 (2009), 1-12.

[3] Z. Dahmani, New inequalities in fractional integrals, Int. J. Nonlinear Sci., 9 (2010), 493-497.

[4] Z. Dahmani and N. Bedjaoui, New generalized integral inequalities, J. Adv. Res. Appl. Math., 3 (2011), 58-66.

[5] Z. Dahmani, New classes of integral inequalities of fractional order, Matematiche (Catania), 69 (2014), 227-235.

[6] Z. Dahmani, On Minkowski and Hermite-Hadamad integral inequalities via fractional integration, Ann. Funct. Anal., 1 (2010), 51-58.

[7] Z. Dahmani, New applications of fractional calculus on probabilistic random variables, Acta Math. Univ. Comenian. (N.S.), 86 (2017), 299-307.

[8] R. Gorenflo and F. Mainardi, Fractional calculus: integral and differential equations of fractional order, Springer Verlag, Wien, 1997, 223-276.

[9] M. Houas, Some new Saigo fractional integral inequalities in quantum calculus, Facta Univ. Ser. Math. Inform., 3 (2016), 761-773.

[10] M. Houas, Certain weighted integral inequalities involving the fractional hypergeometric operators, SCIENTIA, Series A : Mathematical Science, 27 (2016), 87-97.

[11] A.A. Opris, A class of Aczél-Popoviciu type inequality, Gen. Math., 24 (2016), 11-16.

[12] F. Qi, S. Guo and B.N. Guo, Complete monotonicity of some functions involving polygamma functions, J. Comput. Appl. Math., 233 (2010), 2149-2160.

[13] F. Qi and W.H. Li, A logarithmically completely monotonic function involving the ratio of gamma functions, J. Appl. Anal. Comput., 5 (2015), 626-634.

[14] F. Qi, X.A. Li and S.X. Chen, Refinements, extensions and generalizations of the second Kershaw's double inequality, Math. Inequal. Appl., 11 (2008), 457-465.

DOI: 10.24193/mathcluj.2018.2.05 
[15] M.Z. Sarikaya and A. Karaca, On the k-Riemann-Liouville fractional integral and applications, International Journal of Statistics and Mathematics, 1 (2014), 033-043.

[16] M.Z. Sarikaya, and H. Ogunmez, On new inequalities via Riemann-Liouville Fractional Integration, Abstr. Appl. Anal., 2012 (2012), Article 428983, 1-10.

[17] J.F. Tian, Reversed version of a generalized Aczél inequality and its application, J. Inequal. Appl., 2012 (2012), Article 202, 1-8.

[18] J. Tian and S. Wu, New refinements of generalized Aczél inequality and their applications, J. Math. Inequal., 10 (2016), 247-259.

[19] S. Wu and L. Debnath, Generalizations of Aczél's inequality and Popoviciu's inequality, Indian J. Pure Appl. Math., 36 (2005), 49-62.

Received November 10, 2017

University of Mostaganem/Shangai University

Accepted January 10, 2018

Department of Mathematics

Algeria

E-mail: doubbibounoua.mohamed@yahoo.fr

University of Mostaganem

Laboratory LPAM, UMAB

Algeria

E-mail: zzdahmani@yahoo.fr

E-mail: aekm27@yahoo.fr 